Research

\title{
Tissue Doppler in critical illness: a retrospective cohort study
}

\author{
David J Sturgess 1,2 , Thomas H Marwick ${ }^{2,3}$, Christopher J Joyce ${ }^{2,4}$, Mark Jones ${ }^{5}$ and \\ Bala Venkatesh ${ }^{1,2,4}$
}

\author{
${ }^{1}$ Department of Intensive Care, The Wesley Hospital, Coronation Drive, Brisbane, Queensland, Australia 4066 \\ ${ }^{2}$ School of Medicine, University of Queensland, Princess Alexandra Hospital, Ipswich Road, Brisbane, Queensland, Australia 4102 \\ ${ }^{3}$ Department of Echocardiography, Princess Alexandra Hospital, Ipswich Road, Brisbane, Queensland, Australia 4102 \\ ${ }^{4}$ Department of Intensive Care, Princess Alexandra Hospital, Ipswich Road, Brisbane, Queensland, Australia 4102 \\ ${ }^{5}$ School of Population Health, University of Queensland, Princess Alexandra Hospital, Ipswich Road, Brisbane, Queensland, Australia 4102 \\ Corresponding author: David J Sturgess, d.sturgess@uq.edu.au
}

Received: 14 Apr 2007 Revisions requested: 11 May 2007 Revisions received: 15 Aug 2007 Accepted: 6 Sep 2007 Published: 6 Sep 2007

Critical Care 2007, 11:R97 (doi:10.1186/cc6114)

This article is online at: http://ccforum.com/content/11/5/R97

(c) 2007 Sturgess et al.; licensee BioMed Central Ltd.

This is an open access article distributed under the terms of the Creative Commons Attribution License (http://creativecommons.org/licenses/by/2.0), which permits unrestricted use, distribution, and reproduction in any medium, provided the original work is properly cited.

\begin{abstract}
Background There is a paucity of published data on tissue Doppler imaging (TDI) in the critically ill. In a critically ill cohort, we studied the distribution of TDI and its correlation with other echocardiographic indices of preload. To aid hypothesis generation and sample size calculation, associations between echocardiographic variables, including the ratio of peak early diastolic transmitral velocity $(E)$ to peak early diastolic mitral annular velocity $\left(E^{\prime}\right)$, and mortality were also explored.

Methods This retrospective study was performed in a combined medical/surgical, tertiary referral intensive care unit. Over a 2year period, 94 consecutive patients who underwent transthoracic echocardiography with $E / E^{\prime}$ measurement were studied.

Results Mean Acute Physiology and Chronic Health Evaluation III score was $72 \pm 25$. Echocardiography was performed $5 \pm 6$ days after intensive care unit admission. TDI variables exhibited a wide range ( $E^{\prime} 4.7-18.2 \mathrm{~cm} / \mathrm{s}$ and $E / E^{\prime} 3.3$ to 27.2). $E^{\prime}$ below $9.6 \mathrm{~cm} / \mathrm{s}$ was observed in 63 patients (rate of myocardial
\end{abstract}

relaxation below lower 95\% confidence limit of normal individuals). Fourteen patients had E/E' above 15 (evidence of raised left ventricular filling pressure). E/E' correlated with left atrial area $(r=0.27, P=0.01)$ but not inferior vena cava diameter $(r=0.16, P=0.21)$ or left ventricular end-diastolic volume $(r=0.16, P=0.14)$. In this cohort, increased left ventricular end-systolic volume, but not $E / E^{\prime}$, appeared to be an independent predictor (odds ratio 2.1, $P=0.007$ ) of 28-day mortality $(31 \% ; n=29)$.

Conclusion There was a wide range of TDI values. TDI evidence of diastolic dysfunction was common. E/E' did not correlate strongly with other echocardiographic indices of preload. Further evaluation of echocardiographic variables, particularly left ventricular end-systolic volume, for risk stratification in the critically ill appears warranted.

\section{Introduction}

Myocardial dysfunction is common in critically ill patients. Causes include ischaemia, trauma, surgery, sepsis, drugs and toxins. Transthoracic echocardiography is gaining acceptance as a powerful diagnostic tool in this setting [1]. In recent years, tissue Doppler imaging (TDI) has gained increasing acceptance as a means of noninvasively assessing myocardial properties [2] and estimating ventricular filling pressure $[3,4]$, and as a prognostic tool in cardiac diseases $[5,6]$. However, there is a paucity of published data on TDI in critical illness.

TDI is an echocardiographic technique that measures myocardial velocities [7], which are low frequency, high-amplitude signals filtered from conventional Doppler imaging [8]. The peak early diastolic mitral annular velocity ( $\left.E^{\prime}\right)$, as measured using TDI, is a relatively preload insensitive assessment of left ventricular relaxation [9]. Although this variable is not independent

$\overline{\mathrm{APACHE}}=$ Acute Physiology and Chronic Health Evaluation; $\mathrm{E}=$ peak early diastolic transmitral velocity; $\mathrm{E}^{\prime}=$ peak early diastolic mitral annular velocity; ICU = intensive care unit; IVC = inferior vena cava; LA = left atrial; LVEDV = left ventricular end-diastolic volume; LVESV = left ventricular endsystolic volume; TDI = tissue Doppler imaging. 
of large, acute changes in preload (for example, during dialysis [10] or vena caval occlusion [11]), it appears to be less influenced by preload in the critically ill [10]. Also, it does not pseudo-normalize in the same way that transmitral flow does [12]. The influence of changes in ventricular loading on $E^{\prime}$ in critically ill patients remains incompletely defined [13].

Peak early diastolic transmitral velocity $(E)$ is dependent on left ventricular filling pressure, as well as the rate and extent of left ventricular relaxation [14]. The ratio of $E$ to $E^{\prime}(E / E$ ') has been proposed as an estimate of left ventricular filling pressure that corrects $E$ velocity for the influence of myocardial relaxation $[3,4]$. There are scant published data regarding the use of TDI in critical care.

The primary aims of this preliminary study were twofold. First, we wished to assess the distribution of values of TDI in critically ill patients. TDI evidence of diastolic dysfunction was accepted as E' below $9.6 \mathrm{~cm} / \mathrm{s}$ (myocardial relaxation below the lower $95 \%$ confidence limit of normal individuals) [15] or E/E' above 15 (mean left ventricular end-diastolic pressure $>15 \mathrm{mmHg}$ ) [4]. Second, we wished to examine the relationship between TDI (E/E') and other echocardiographic variables. This included left ventricular volumes and alternative indices of ventricular filling pressure such as left atrial size [16] and inferior vena cava (IVC) maximal diameter (right heart) [17].

TDI and other echocardiographic indices have shown prognostic significance in patients with cardiac diseases $[5,6,18,19]$. No comparable data have been described in the critically ill. This study incorporated a secondary aim of exploring associations between echocardiographic variables, particularly $E / E^{\prime}$, and mortality. This was undertaken with the intention of hypothesis generation and sample size calculation, with a view to conducting a prospective evaluation in the future.

\section{Materials and methods Patients}

Between January 2003 and December 2004 inclusive, 2,695 patients were admitted to the intensive care unit (ICU) of the Princess Alexandra Hospital, Brisbane, Australia, which is an adult medical/surgical tertiary referral ICU. Echocardiography and ICU databases were cross-referenced and yielded a total of 277 clinically requested echocardiograms, performed in 202 patients. Of these, 94 patients included measurement of $E / E '$. These patients were enrolled. In each case, the first echocardiogram supplemented by measurement of $E / E^{\prime}$ was studied. Approval for retrospective analysis of clinical data was granted by the Princess Alexandra Hospital Human Research Ethics Committee (protocol number 2005/028).

\section{Clinical and outcome data}

The Acute Physiology and Chronic Health Evaluation (APACHE) III database (Cerner APACHE III ${ }^{\circledR}$; Cerner Corporation, MO, USA) was used to source clinical data, including sex, date of birth, admission and discharge dates, principal reason for ICU admission, ICU and hospital mortality. The APACHE III score and derived risk predictions [20] were also obtained for each patient.

\section{Echocardiography}

All examinations were performed by experienced sonographers using commercially available equipment. Digitally stored images were analyzed by a single observer who was blinded to clinical and outcome data. Measurements were made using AccessPoint ${ }^{\mathrm{TM}} 2000$ software (Freeland Systems, Westfield, IN, USA). Unless otherwise stated, measurements were recorded at end-expiration.

Left ventricular end-diastolic volume (LVEDV) and left ventricular end-systolic volume (LVESV) were calculated using the biplane method of disks (modified Simpson's rule) from the apical four-chamber and two-chamber views [21]. Left ventricular ejection fraction and stroke volume were calculated from LVEDV and LVESV using standard formulae. IVC maximal diameter, independent of respiratory phase, was measured from subcostal views. Zoomed images of the apical four-chamber view were used to measure left atrial (LA) area, and perpendicular $L A$ major $(L)$ and minor $\left(D_{1}\right)$ axes. LA minor axis $\left(D_{2}\right)$ was measured from the parasternal long axis view. LA volume was calculated using an ellipsoid model (American Society of Echocardiography guidelines) [21]:

Volume $=4 \pi / 3 \times(L / 2) \times\left(D_{1} / 2\right) \times\left(D_{2} / 2\right)$

Transmitral flow velocities were recorded with pulsed wave Doppler with the sample volume placed at the mitral valve tips from the apical four-chamber view. Peak passive and active velocities were recorded.

Myocardial velocities were obtained using tissue Doppler settings, with the pulsed wave Doppler sample volume at the septal mitral annulus in the apical four-chamber view. Myocardial diastolic velocity (E') was measured and E/E' was calculated.

In the presence of atrial dysrhythmia, transmitral and tissue Doppler velocities were measured over at least five consecutive cardiac cycles.

\section{Statistical analysis}

Analysis was performed by SPSS, version 14.0 for Windows (SPSS Inc., Chicago, IL, USA) and SAS version 9.1 for Windows (SAS Institute, Cary, NC, USA).

Descriptive measures were used to determine the distribution of echocardiographic variables. Differences between groups 
were assessed using $\chi^{2}$ tests for categorical data. Continuous data were assessed using Levene's test for equality of variance before performing Student's $t$-test for independent samples. Pearson's correlation coefficient was used to examine the relationship between TDI and other echocardiographic variables.

Cox proportional hazards regression was used for time to event outcomes (28-day mortality) from the date of echocardiography. A cut-off $P$ value of $<0.1$ was used to determine whether predictor variables in univariate models would be selected for inclusion in multiple regression models. A backward elimination procedure was then used to discard all predictor variables with $P<0.1$ in multiple regression models, one by one, until a final 'best' model was achieved. $P$ values relating to survival plots were taken from Log rank tests. In final analyses, $P<0.05$ was regarded as significant. Unless stated otherwise, results are reported as mean \pm standard deviation.

\section{Results}

\section{Patient characteristics}

The study cohort consisted of 28 females (30\%) and 66 males (70\%), with a mean age of $61 \pm 15$ years. Transthoracic echocardiography was performed a mean of $5 \pm 6$ days from ICU admission (61\% within 3 days of ICU admission). Inspection of data (Table 1) reveals that the study cohort had a higher severity of illness than that in the general ICU population during the same period. On the day of echocardiography, 37 out of the 94 patients were mechanically ventilated. At the time of echocardiography, atrial fibrillation was present in four (4\%) participants. None had atrial flutter.

\section{Echocardiography}

Echocardiographic characteristics of the cohort are presented in Table 2. Values of $E^{\prime}$ ranged from 4.7 to $18.2 \mathrm{~cm} / \mathrm{s}$, with $67 \%(n=63)$ demonstrating impaired myocardial relaxation $\left(E^{\prime}<9.6 \mathrm{~cm} / \mathrm{s}\right)$. In the absence of defined reference ranges for the critically ill, a cut-off of $9.6 \mathrm{~cm} / \mathrm{s}$ was accepted. This represents the lower $95 \%$ confidence limit for segmental $E^{\prime}$ in nor- mal individuals [15]. Based on the E/E' ratio alone, 26 patients demonstrated normal left ventricular filling pressure $\left(E / E^{\prime}<8\right)$ whereas 14 had raised filling pressure $\left(E / E^{\prime}>15\right)$ [4]. The remaining 54 patients had $E / E^{\prime}$ in the intermediate range.

There was no significant difference in the value of $E^{\prime}$ between ventilated and nonventilated patients $(8.8 \pm 2.9 \mathrm{~cm} / \mathrm{s}$ versus $8.8 \pm 3 \mathrm{~cm} / \mathrm{s}$, respectively; $P=0.9$ [equal variance assumed; Levene's test $P=1.0]$ ). Likewise, the value of $E / E^{\prime}$ did not differ significantly between ventilated and nonventilated patients (11.1 \pm 4.5 versus $10.7 \pm 4.6$, respectively; $P=0.7$ [equal variance assumed; Levene's test $P=0.89]$ ). The mechanically ventilated group exhibited an increased IVC maximal diameter compared with the nonventilated group $(2.3 \pm 0.5 \mathrm{~cm}$ versus $1.9 \pm 0.5 \mathrm{~cm}$, respectively; $P=0.015$ [equal variance assumed; Levene's test $P=0.88]$ ).

When all patients were included, there were no significant correlations between $E^{\prime}$ and the other echocardiographic variables (other than E/E' ratio). Subgroup analysis of patients who were mechanically ventilated on the day of echocardiography revealed a correlation between $\mathrm{E}^{\prime}$ and heart rate $(r=0.265, P$ $=0.048$ ).

The correlation between E/E' and other echocardiographic indices of preload were as follows: E/E' ratio versus $\mathrm{LA}$ area, $r$ $=0.27(P=0.01) ; \mathrm{E} / \mathrm{E}^{\prime}$ ratio versus LVEDV, $r=0.16(P=$ $0.14)$; and $\mathrm{E} / \mathrm{E}^{\prime}$ ratio versus IVC diameter, $r=0.16(P=0.21)$. In mechanically ventilated patients, the correlation between $\mathrm{E} /$ $\mathrm{E}^{\prime}$ and LA area was significant $(r=0.3, P=0.026)$; however, this relationship was not observed in the nonventilated group $(r=0.21, P=0.22)$.

\section{Associations with mortality}

The all-cause ICU mortality rate was $23 \%$, and corresponding 28-day and hospital mortality rates were $31 \%$ and $33 \%$, respectively.

Univariate analysis yielded significant associations between

Table 1

Demographic data of the study cohort and all ICU patients between January 2003 and December 2004

\begin{tabular}{llll}
\hline Characteristic & Cohort $(n=94)$ & ICU patients $(n=2,695)$ & $P$ \\
\hline Female sex & $28(31 \%)$ & $808(30 \%)$ & $\leq 1$ \\
Age (years) & $61 \pm 15$ & $58 \pm 17$ & 0.065 \\
APACHE III score & $72 \pm 25$ & $53 \pm 25$ & $\leq 0.001$ \\
Length of ICU stay (days) & $11.5 \pm 11$ & $3.5 \pm 6.5$ & $\leq 0.001^{\mathrm{a}}$ \\
Length of hospital stay (days) & $32 \pm 48$ & $19 \pm 29$ & $0.01^{\mathrm{a}}$ \\
ICU mortality & $22(23 \%)$ & $201(7.5 \%)$ & $\leq 0.001$ \\
Hospital mortality & $31(33 \%)$ & $309(11.5 \%)$ & $\leq 0.001$
\end{tabular}

Results are expressed as mean \pm standard deviation or number (percentage). aUnequal variance assumed (Levene's test $P<0.001)$. APACHE, Acute Physiology and Chronic Health Evaluation; ICU, intensive care unit; database. 
Table 2

Echocardiographic characteristics of patients

\begin{tabular}{lll}
\hline Characteristic & Cohort $(n=94)$ & Reference range \\
\hline $\mathrm{E}(\mathrm{m} / \mathrm{s})$ & $0.89(0.3$ to 1.9$)$ & 0.44 to 1.0 \\
$\mathrm{~A}(\mathrm{~m} / \mathrm{s})$ & $0.79(0.3$ to 2$)$ & 0.2 to 0.6 \\
$\mathrm{E}^{\prime}(\mathrm{cm} / \mathrm{s})$ & $8.8(4.7$ to 18.2$)$ & 9.6 to 11 \\
E/E' ratio & $10.96(3.3$ to 27.2$)$ & $<8$ \\
LA area $\left(\mathrm{cm}^{2}\right)$ & $24(8$ to 40$)$ & $\leq 20$ \\
LA volume $(\mathrm{ml})$ & $57(10$ to 99$)$ & 22 to 58 \\
LVEDV $(\mathrm{ml})$ & $129(42$ to 378$)$ & 56 to 155 \\
LVESV $(\mathrm{ml})$ & $74(5$ to 264$)$ & 19 to 58 \\
LV stroke volume $(\mathrm{ml})$ & $54(10$ to 137$)$ & $\geq 55$ \\
LV ejection fraction $(\%)$ & $47(7$ to 93$)$ & $<1.7$ \\
IVC diameter $(\mathrm{cm})$ & $2.1(1.1$ to 3.3$)$ & \\
\hline
\end{tabular}

Results are expressed as mean (range). Reference ranges are not specific for critically ill patients $[4,15,21,33]$. A, peak active transmitral velocity; $\mathrm{E}$, peak early diastolic (passive) transmitral velocity; E', peak early diastolic mitral annular velocity; IVC, inferior vena cava; LA, left atrial; LV, left ventricular; LVEDV, left ventricular end-diastolic volume; LVESV, left ventricular end-systolic volume.

28-day mortality and APACHE III predicted hospital death, LVEDV and LVESV (Table 3). In this cohort, LVESV was also an independent predictor of mortality. The resultant odds ratio suggests that the risk for death approximately doubles for each $100 \mathrm{ml}$ increase in LVESV. However, log rank analysis reveals that only LVESV greater than $105 \mathrm{ml}$ (highest quintile) was associated with a significantly different Kaplan-Meier curve (Figure 1).

Comparison between survivors and nonsurvivors at 28 days revealed no significant differences in $E^{\prime}(8.7 \pm 2.7 \mathrm{~cm} / \mathrm{s}$ versus $9.1 \pm 3.5 \mathrm{~cm} / \mathrm{s}, P=0.58)$, E/E' ratio (10.8 \pm 4.8 versus 11.4 $\pm 3.9, P=0.5)$, LA area $\left(23.3 \pm 6.4 \mathrm{~cm}^{2}\right.$ versus $25.6 \pm 6.7$ $\left.\mathrm{cm}^{2}, P=0.14\right)$, or IVC maximal diameter $(2.0 \pm 0.5 \mathrm{~cm}$ versus $2.2 \pm 0.5 \mathrm{~cm}, P=0.13$ ).

\section{Discussion}

This study was performed in response to increasing utilization of echocardiography in our ICU. TDI is routinely performed by our echocardiographers as part of a comprehensive transthoracic echocardiography examination. Although there are increasing data supporting the role of TDI in clinical cardiology [12], there are scant data regarding its application to critical care.

In this study of critically ill patients, the clinical decision to perform echocardiography selected a cohort with high severity of illness (mean APACHE III score 72). A wide range of echocardiographic values were observed. Extreme values, such as LVESV of $5 \mathrm{ml}$ and left ventricular ejection fraction of $7 \%$, reflect the high severity of illness.
The cardinal findings of this study were as follows. First, there was a wide range of $E^{\prime}$ values $(4.7$ to $18.2 \mathrm{~cm} / \mathrm{s})$, with a mean of $8.8 \mathrm{~cm} / \mathrm{s}$. Approximately two-thirds of the cohort exhibited TDI evidence of delayed myocardial relaxation $\left(E^{\prime}<9.6 \mathrm{~cm} / \mathrm{s}\right)$. Second, there was a wide range of $E / E^{\prime}$ ratios (3.3 to 27.2). The mean value (10.96) is within the intermediate range for left ventricular end-diastolic pressure. Of the cohort, 15\% $(n=14)$ demonstrated Doppler evidence of elevated left ventricular filling pressure $\left(E / E^{\prime}>15\right)$. Third, there was a weak correlation between E/E' and LA area. On subgroup analysis, this correlation persisted only in the mechanically ventilated patients. No correlations were demonstrated between E/E' and LA volume, IVC diameter, or LVEDV. Finally, in the selected cohort, increased LVESV, but not E' or E/E', was associated with excess 28-day mortality.

In this preliminary retrospective study, we were able to define a range of TDI values for a cohort of critically ill patients. This extends previously published data. TDI evidence of diastolic dysfunction was common in this critically ill cohort. There was TDI evidence of impaired myocardial relaxation in two-thirds of the patients, and elevated left ventricular filling pressure in $15 \%$ or more.

Robust diagnosis of diastolic dysfunction is difficult regardless of the method of evaluation [22]. Although cardiac catheterization and measurement of intracardiac pressures allow analysis of pressure-volume loops and rates/time constants of pressure change, these techniques are impractical in critical care. Echocardiography, on the other hand, is a readily available bedside tool. It is safe in critically ill patients and is increasingly accepted in their care [1]. 

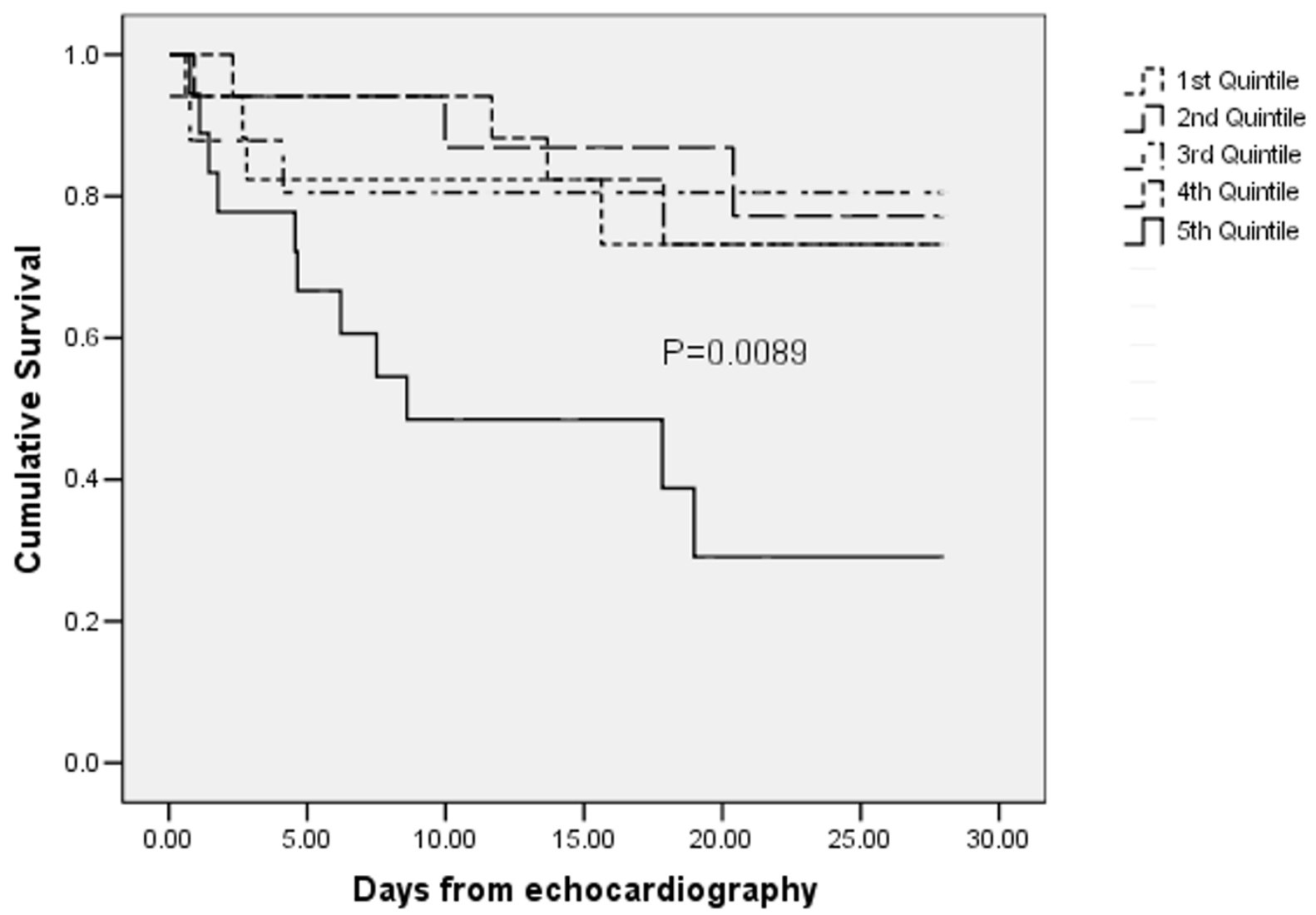

-1 1st Quintile
7 2nd Quintile
-7 3rd Quintile
7 4th Quintile
5th Quintile

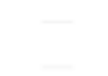


Table 3

Clinical and echocardiographic correlates of 28-day mortality

\begin{tabular}{|c|c|c|c|c|}
\hline \multirow[t]{2}{*}{ Variable } & \multicolumn{2}{|c|}{ Univariate } & \multicolumn{2}{|c|}{ Multiple regression } \\
\hline & OR $(95 \% \mathrm{Cl})$ & $P$ & OR $(95 \% \mathrm{Cl})$ & $P$ \\
\hline Female sex & 0.85 (0.38 to 1.9$)$ & 0.7 & & \\
\hline Age (per decade) & 1.03 (0.8 to 1.3$)$ & 0.8 & & \\
\hline APACHE III predicted hospital death $(\times 10)^{a}$ & $1.18(1.03$ to 1.4$)$ & 0.017 & $1.3(1.1$ to 1.5$)$ & 0.0028 \\
\hline$E(\mathrm{~m} / \mathrm{s})$ & $2.3(0.7$ to 7.6$)$ & 0.16 & & \\
\hline$A(\mathrm{~m} / \mathrm{s})$ & $0.74(0.22$ to 2.5$)$ & 0.6 & & \\
\hline $\mathrm{E}^{\prime}(\times 10 \mathrm{~cm} / \mathrm{s})^{\mathrm{a}}$ & $1.0(0.5$ to 1.9$)$ & 0.9 & & \\
\hline E/E' ratio $(/ 10)^{a}$ & $1.3(0.6$ to 2.8$)$ & 0.5 & & \\
\hline LA area $\left(/ 10 \mathrm{~cm}^{2}\right)^{\mathrm{a}}$ & 1.5 (0.8 to 2.9$)$ & 0.19 & & \\
\hline LA volume $(/ 100 \mathrm{~mL})^{a}$ & $1.4(0.22$ to 9$)$ & 0.7 & & \\
\hline LVEDV $(/ 100 \mathrm{~mL})^{\mathrm{a}}$ & 2.0 (1.2 to 3.3$)$ & 0.0059 & & \\
\hline LVESV (/100 mL)a & $2.2(1.3$ to 3.8$)$ & 0.0047 & 2.1 (1.2 to 3.7$)$ & 0.0068 \\
\hline LV stroke volume (/100 mL)a & $1.4(0.32$ to 6.1$)$ & 0.7 & & \\
\hline LV ejection fraction (/100\%)a & $0.24(0.03$ to 1.7$)$ & 0.15 & & \\
\hline IVC diameter (cm) & $1.8(0.8$ to 4.1$)$ & 0.14 & & \\
\hline
\end{tabular}

For multiple regression analysis, only variables included in the final best model are shown. The scale of these variables was altered by the amount shown in parentheses to aid interpretation of odds ratios. A, peak active transmitral velocity; APACHE, Acute Physiology and Chronic Health

Evaluation; $\mathrm{Cl}$, confidence interval; E, peak early diastolic (passive) transmitral velocity; $\mathrm{E}^{\prime}$, peak early diastolic mitral annular velocity; IVC, inferior vena cava; LA, left atrial; LV, left ventricular; LVEDV, left ventricular end-diastolic volume; LVESV, left ventricular end-systolic volume; OR, odds ratio.

It was not possible to assess the contribution of therapy or underlying pathology.

$E^{\prime}$ and $E / E^{\prime}$ were not predictors of mortality in the selected cohort. This differs from other published data [5,6,29-31]. The lack of association of TDI ( $E^{\prime}$ and $E / E^{\prime}$ ) with outcome may attest to these signals being influenced by therapeutic measures as much as being markers of underlying disease. This is an important consideration in evaluating TDI as a prognostic indicator in the critically ill. Prospective evaluation should account for haemodynamic status and concurrent therapeutic intervention. Another consideration is the potential prognostic relevance of changes in these variables over time. For instance, worsening diastolic function despite appropriate therapy might be a more sensitive indicator of unfavourable prognosis.

Another consideration for prospective evaluation is sample size calculation. Accepting a 28-day mortality of $31 \%$ and $\alpha$ of 0.05 , the number of nonsurvivors required to achieve $80 \%$ power was calculated for the following variables [32]: E' 1,136 nonsurvivors (difference between means $[\delta]=0.3$, standard deviation $[\sigma]=3)$; E/E' 429 nonsurvivors $(\delta=0.7, \sigma=4.3) ; \mathrm{LA}$ area 90 nonsurvivors $(\delta=2.32, \sigma=6.5)$, and IVC maximal diameter 65 nonsurvivors $(\delta=0.21, \sigma=0.5)$.

\section{Study limitations}

The cohort presented here represents a consecutive group of patients in whom E/E' was performed on clinical grounds, thus increasing the potential for selection bias. Echocardiography was not routinely performed at the time of hospital or ICU admission. It is likely that the results would be influenced by timing of echocardiography relative to initiation and progress of therapy.

This study incorporated a secondary aim of exploring associations between echocardiographic variables, particularly $E / E^{\prime}$, and mortality. It is unlikely that any isolated echocardiographic measurement taken at a variable point in the disease/treatment process will contribute to risk stratification. However, this important limitation was accepted with the intention being to generate hypotheses that can be tested prospectively. Timing of echocardiography and concurrent interventions should be considered in planning prospective evaluation.

Despite these methodological issues, the novel aspects of the study include the generation of potential reference ranges for TDI indices in critically ill patients, which can provide a framework for planning future studies. The findings of this retrospective, single centre study should be confirmed by a larger, prospective and multicentre study. 


\section{Conclusion}

This critically ill cohort exhibited a wide range of TDI values. Diastolic dysfunction, as evidenced by TDI, was common in this critically ill cohort. E/E' did not correlate strongly with other echocardiographic indices of preload. Further evaluation of echocardiographic variables, particularly increased LVESV, for risk stratification in the critically ill appears warranted.

\section{Key messages}

- There was a wide range of $E^{\prime}$ value (mean $8.8 \mathrm{~cm} / \mathrm{s}$; range 4.7 to $18.2 \mathrm{~cm} / \mathrm{s}$ ) and $E / E^{\prime}$ ratios (mean 10.96, range 3.3 to 27.2 ).

- Approximately two-thirds of the cohort exhibited TDI evidence of delayed myocardial relaxation $\left(E^{\prime}<9.6 \mathrm{~cm} / \mathrm{s}\right)$.

- Fifteen percent $(n=14)$ of the cohort demonstrated Doppler evidence of elevated left ventricular filling pressure $\left(E / E^{\prime}>15\right)$.

- There was a weak correlation between E/E' and LA area, which persisted only in the mechanically ventilated patients; no correlations were demonstrated with LA volume, IVC diameter, or LVEDV.

- In the selected cohort, increased LVESV, but not E' or $E / E^{\prime}$, was associated with excess 28-day mortality.

\section{Competing interests}

The authors declare that they have no competing interests.

\section{Authors' contributions}

DS conceived of the study, and participated in its design and coordination, and drafted the manuscript. TM conceived of the study, and participated in its design and helped to draft the manuscript. CJ participated in the design of the study and helped to draft the manuscript. MJ participated in the design of the study and performed the statistical analysis. BV conceived of the study, and participated in its design and helped to draft the manuscript. All authors read and approved the final manuscript.

\section{Acknowledgements}

This study was conducted with the support of grants from the PA Foundation and the Australian and New Zealand College of Anaesthetists. The authors also thank Mr Rod Hurford, an employee of Queensland Health, for his contribution to database construction and interrogation.

This study was performed at The University of Queensland, the Department of Intensive Care and the Department of Echocardiography, Princess Alexandra Hospital, Ipswich Road, Brisbane, Australia, 4102.

This paper was presented in poster format at the 2006 American Heart Association Scientific Sessions (November; Chicago, IL, USA) and at the 2007 International Symposium on Intensive Care and Emergency Medicine (March; Brussels, Belgium).

\section{References}

1. Cholley BP, Vieillard-Baron A, Mebazaa A: Echocardiography in the ICU: time for widespread use! Intensive Care Med 2006, 32:9-10.

2. Gulati VK, Katz WE, Follansbee WP, Gorcsan J III: Mitral annular descent velocity by tissue Doppler echocardiography as an index of global left ventricular function. $A m J$ Cardiol 1996, 77:979-984.

3. Nagueh SF, Middleton KJ, Kopelen HA, Zoghbi WA, Quinones MA: Doppler tissue imaging: a noninvasive technique for evaluation of left ventricular relaxation and estimation of filling pressures. J Am Coll Cardiol 1997, 30:1527-1533.

4. Ommen SR, Nishimura RA, Appleton CP, Miller FA, Oh JK, Redfield MM, Tajik AJ: Clinical utility of Doppler echocardiography and tissue Doppler imaging in the estimation of left ventricular filling pressures: a comparative simultaneous Doppler-catheterization study. Circulation 2000, 102:1788-1794.

5. Wang M, Yip GW, Wang AY, Zhang Y, Ho PY, Tse MK, Lam PK, Sanderson JE: Peak early diastolic mitral annulus velocity by tissue Doppler imaging adds independent and incremental prognostic value. J Am Coll Cardiol 2003, 41:820-826.

6. Hillis GS, Moller JE, Pellikka PA, Gersh BJ, Wright RS, Ommen SR, Reeder GS, Oh JK: Noninvasive estimation of left ventricular filling pressure by $E / E^{\prime}$ is a powerful predictor of survival after acute myocardial infarction. J Am Coll Cardiol 2004, 43:360-367.

7. Isaaz K, Thompson A, Ethevenot G, Cloez JL, Brembilla B, Pernot C: Doppler echocardiographic measurement of low velocity motion of the left ventricular posterior wall. Am J Cardio/ 1989, 64:66-75.

8. Dokainish $\mathrm{H}$ : Tissue Doppler imaging in the evaluation of left ventricular diastolic function. Curr Opin Cardiol 2004, 19:437-441.

9. Sohn DW, Chai IH, Lee DJ, Kim HC, Kim HS, Oh BH, Lee MM, Park YB, Choi YS, Seo JD, et al.: Assessment of mitral annulus velocity by Doppler tissue imaging in the evaluation of left ventricular diastolic function. J Am Coll Cardiol 1997, 30:474-480.

10. Vignon $P$, Allot V, Lesage J, Martaille JF, Aldigier JC, Francois B, Gastinne $\mathrm{H}$ : Diagnosis of left ventricular diastolic dysfunction in the setting of acute changes in loading conditions. Crit Care 2007, 11:R43.

11. Jacques DC, Pinsky MR, Severyn D, Gorcsan J III: Influence of alterations in loading on mitral annular velocity by tissue Doppler echocardiography and its associated ability to predict filling pressures. Chest 2004, 126:1910-1918.

12. Marwick TH: Clinical applications of tissue Doppler imaging: a promise fulfilled. Heart 2003, 89:1377-1378.

13. Poelaert J, Roosens C: Is tissue Doppler echocardiography the Holy Grail for the intensivist? Crit Care 2007, 11:135.

14. Choong CY, Abascal VM, Thomas JD, Guerrero JL, McGlew S, Weyman $A E$ : Combined influence of ventricular loading and relaxation on the transmitral flow velocity profile in dogs measured by Doppler echocardiography. Circulation 1988, 78:672-683.

15. Garcia-Fernandez MA, Azevedo J, Moreno M, Bermejo J, PerezCastellano N, Puerta P, Desco M, Antoranz C, Serrano JA, Garcia $\mathrm{E}$, et al:: Regional diastolic function in ischaemic heart disease using pulsed wave Doppler tissue imaging. Eur Heart J 1999 , 20:496-505.

16. Appleton CP, Galloway JM, Gonzalez MS, Gaballa M, Basnight MA: Estimation of left ventricular filling pressures using twodimensional and Doppler echocardiography in adult patients with cardiac disease. Additional value of analyzing left atrial size, left atrial ejection fraction and the difference in duration of pulmonary venous and mitral flow velocity at atrial contraction. J Am Coll Cardiol 1993, 22:1972-1982.

17. Moreno FL, Hagan AD, Holmen JR, Pryor TA, Strickland RD, Castle $\mathrm{CH}$ : Evaluation of size and dynamics of the inferior vena cava as an index of right-sided cardiac function. Am J Cardio/ 1984 , 53:579-585

18. White HD, Norris RM, Brown MA, Brandt PW, Whitlock RM, Wild CJ: Left ventricular end-systolic volume as the major determinant of survival after recovery from myocardial infarction. Circulation 1987, 76:44-51.

19. Moller JE, Hillis GS, Oh JK, Seward JB, Reeder GS, Wright RS, Park SW, Bailey KR, Pellikka PA: Left atrial volume: a powerful 
predictor of survival after acute myocardial infarction. Circulation 2003, 107:2207-2212.

20. Knaus WA, Wagner DP, Draper EA, Zimmerman JE, Bergner M, Bastos PG, Sirio CA, Murphy DJ, Lotring T, Damiano A, et al:: The APACHE III prognostic system. Risk prediction of hospital mortality for critically ill hospitalized adults. Chest 1991, 100:1619-1636.

21. Lang RM, Bierig M, Devereux RB, Flachskampf FA, Foster E, Pellikka PA, Picard MH, Roman MJ, Seward J, Shanewise JS, et al:: Recommendations for chamber quantification: a report from the American Society of Echocardiography's Guidelines and Standards Committee and the Chamber Quantification Writing Group, developed in conjunction with the European Association of Echocardiography, a branch of the European Society of Cardiology. J Am Soc Echocardiogr 2005, 18:1440-1463.

22. Sturgess DJ, Marwick TH, Venkatesh B: Diastolic (Dys)Function in Sepsis. In Yearbook of Intensive Care and Emergency Medicine Edited by: Vincent JL. Berlin, Heidelberg: Springer-Verlag; 2007:444-454.

23. Bouhemad B, Nicolas-Robin A, Benois A, Lemaire S, Goarin JP, Rouby JJ: Echocardiographic Doppler assessment of pulmonary capillary wedge pressure in surgical patients with postoperative circulatory shock and acute lung injury. Anesthesiology 2003, 98:1091-1100.

24. Combes A, Arnoult F, Trouillet JL: Tissue Doppler imaging estimation of pulmonary artery occlusion pressure in ICU patients. Intensive Care Med 2004, 30:75-81.

25. Sohn DW, Song JM, Zo JH, Chai IH, Kim HS, Chun HG, Kim HC: Mitral annulus velocity in the evaluation of left ventricular diastolic function in atrial fibrillation. $J \mathrm{Am}$ Soc Echocardiogr 1999, 12:927-931.

26. Simek CL, Feldman MD, Haber HL, Wu CC, Jayaweera AR, Kaul S: Relationship between left ventricular wall thickness and left atrial size: comparison with other measures of diastolic function. J Am Soc Echocardiogr 1995, 8:37-47.

27. St John Sutton M, Pfeffer MA, Plappert T, Rouleau JL, Moye LA, Dagenais GR, Lamas GA, Klein M, Sussex B, Goldman S, et al.: Quantitative two-dimensional echocardiographic measurements are major predictors of adverse cardiovascular events after acute myocardial infarction. The protective effects of captopril. Circulation 1994, 89:68-75.

28. Trehan N, Khanna SN, Mishra Y, Kohli V, Mehta Y, Mishra M, Mittal $S$ : Predictors of early outcome after coronary artery surgery in patients with severe left ventricular dysfunction. J Card Surg 2003, 18:101-106.

29. Dokainish $\mathrm{H}$, Zoghbi WA, Lakkis NM, Ambriz E, Patel R, Quinones MA, Nagueh SF: Incremental predictive power of B-type natriuretic peptide and tissue Doppler echocardiography in the prognosis of patients with congestive heart failure. $J \mathrm{Am}$ Coll Cardiol 2005, 45:1223-1226.

30. Okura H, Takada Y, Kubo T, Iwata K, Mizoguchi S, Taguchi H, Toda I, Yoshikawa J, Yoshida K: Tissue doppler derived index of left ventricular filling pressure, $E / E^{\prime}$, predicts survival in patients with non-valvular atrial fibrillation. Heart 2006, 92:1248-1252.

31. Moller JE, Sondergaard E, Poulsen SH, Seward JB, Appleton CP, Egstrup K: Color M-mode and pulsed wave tissue Doppler echocardiography: powerful predictors of cardiac events after first myocardial infarction. J Am Soc Echocardiogr 2001, 14:757-763.

32. Dupont WD, Plummer WD: PS power and sample size program available for free on the internet. Controlled Clin Trials 1997, 18:274.

33. Cohen GI, Pietrolungo JF, Thomas JD, Klein AL: A practical guide to assessment of ventricular diastolic function using doppler echocardiography. J Am Coll Cardiol 1996, 27:1753-1760. 